\title{
Work Group Diversity
}

\author{
Daan van Knippenberg \\ and Michaéla C. Schippers
}

RSM Erasmus University, Erasmus University Rotterdam, Rotterdam 3000 DR, The Netherlands; email: dvanknippenberg@rsm.nl, mschippers@rsm.nl

Annu. Rev. Psychol. 2007. 58:515-41

First published online as a Review in Advance on August 11, 2006

The Annual Review of Psychology is online at http://psych.annualreviews.org

This article's doi:

10.1146/annurev.psych.58.110405.085546

Copyright (c) 2007 by Annual Reviews. All rights reserved

0066-4308/07/0110-0515\$20.00

\section{Key Words}

group composition, group performance, teams, team effectiveness, organizational behavior

\begin{abstract}
Work group diversity, the degree to which there are differences between group members, may affect group process and performance positively as well as negatively. Much is still unclear about the effects of diversity, however. We review the 1997-2005 literature on work group diversity to assess the state of the art and to identify key issues for future research. This review points to the need for more complex conceptualizations of diversity, as well as to the need for more empirical attention to the processes that are assumed to underlie the effects of diversity on group process and performance and to the contingency factors of these processes.
\end{abstract}




\section{Contents}

WORK GROUP DIVERSITY ...... 516 WORK GROUP DIVERSITY: AN INTRODUCTION IN BROAD STROKES 517

\section{CONCEPTUALIZING}

DIVERSITY

Typologies of Diversity .......... 519

Beyond Demographic and

Functional Diversity......... 521

Beyond Dispersion ........... 522

Faultlines: Interacting Dimensions of Diversity .............. 523

PROCESSES UNDERLYING THE

INFLUENCE OF DIVERSITY

AND THEIR

CONTINGENCIES........... 524

Social Categorization Processes ... 525

Information/Decision-Making

Processes

Social Categorization Processes As

Moderator of Information/

Decision-Making Processes.... 528

Cooperation and

Interdependence .......... 529

Time/Team Tenure............ 530

Diversity Mind-Sets .......... 531

CURVILINEAR

RELATIONSHIPS .......... 532

CONCLUSIONS.............. 532

Diversity: a

characteristic of social grouping that reflects the degree to which objective or subjective differences exist between group members

\section{WORK GROUP DIVERSITY}

Groups in organizations have become increasingly diverse over the years and will continue to become more diverse in years to come (Jackson et al. 2003, Triandis et al. 1994, Williams \& O’Reilly 1998). Organizations have become more diverse in terms of demographic differences between people (e.g., in terms of gender, age, and ethnicity). Moreover, organizations are increasingly adopting work group compositions that incorporate differences in functional or educational background, such as in cross-functional project teams; mergers, acquisitions, and joint ventures also introduce diversity into work groups. Because work group diversity may have positive as well as negative effects on group performance (for reviews, see Jackson et al. 2003, Milliken \& Martins 1996, Williams \& O'Reilly 1998; also see recent $A n$ nual Review of Psychology chapters by Guzzo \& Dickson 1996, Ilgen et al. 2005, Kerr \& Tindale 2004), the questions of which processes underlie these effects of diversity and how to manage these processes pose major challenges to research in organizational behavior. In the present article, we aim to assess the state of the art in this field. In doing so, we strive to answer the question of what we may conclude from the extant research as well as to provide a research agenda for diversity research in years to come.

Although the field is known as "organizational diversity," theory and research focus almost exclusively on the work group level, studying how group composition affects group performance, cohesion, and social interaction, and group members' commitment, satisfaction, and other indicators of subjective well-being. This review, therefore, focuses on work group diversity and how it affects groups and their members. Diversity is a group characteristic, but there is a stream of research on what is called relational demography (Chattopadhyay et al. 2004a, Tsui \& O'Reilly 1989) that studies the effects of individuals' similarity to their work group (e.g., Chatman \& Flynn 2001, Chatman \& O'Reilly 2004, Chattopadhyay 1999, Chattopadhyay \& George 2001) or to their leader (Epitropaki \& Martin 1999, Tsui et al. 2002) as predictors of individual outcomes. Because greater dissimilarity from the group does not necessarily imply greater work group diversity (e.g., a sole female in an otherwise allmale group is very dissimilar to the group in terms of gender, while at the same time the group is quite gender-homogeneous), results from studies on relational demography cannot be taken to directly reflect diversity effects. Space limitations force us to restrict the current review to studies of diversity as a group 
characteristic, although we do refer to relational demography studies when they seem relevant to the issue under consideration.

The starting point for our article is a seminal review by Williams \& O'Reilly (1998), who examined 40 years of diversity research covering more than 80 studies. The Williams \& O'Reilly review is an important milestone not only because it provides a comprehensive review of the diversity literature at the time, but also because it is somewhat of a watershed in diversity research. The state of the field that emerged from the Williams \& O'Reilly review is one that has yielded largely inconsistent results, probably in part as a result of a somewhat too simplified approach to diversity. In the years following the review, however, the field moved to more sophisticated conceptualizations of diversity and its effects, and we hope to capture this development in the present review. We take the excellent work done by Williams \& O'Reilly as a steppingstone and review diversity research in the period from 1997 to 2005.

To access the relevant literature, we conducted a PsycInfo search of titles and abstracts covering this period and a manual search of the 2000-2005 volumes of major journals in applied psychology and organizational behavior. We also sent out a mailing to solicit papers in press. We should note, however, that our aim is not an exhaustive coverage of the literature, but rather a more selective review that highlights the developments we judge to be most relevant and important.

In the following sections, we first introduce the research field. Second, we address the issue of the conceptualization and operationalization of diversity, arguing in favor of more complex conceptualizations of diversity than typically have been used in diversity research. Next, we focus on what we may learn about the processes underlying the effects of work group diversity by reviewing studies of the mediators and moderators of the effects of diversity, and we briefly touch on possible curvilinear effects of diversity. We conclude by summarizing what we see as the most im- portant questions for future research. These questions center around the need to develop conceptualizations of diversity that go beyond mere dispersion as well as the need to pay greater attention to the processes mediating the effects of diversity and to the contingencies of these processes.

\section{WORK GROUP DIVERSITY: AN INTRODUCTION IN BROAD STROKES}

Diversity is typically conceptualized as referring to differences between individuals on any attribute that may lead to the perception that another person is different from self (Jackson 1992, Triandis et al. 1994, Williams \& O'Reilly 1998). In principle, diversity research may concern any possible dimension of differentiation, but in practice diversity research has primarily focused on differences in gender, age, ethnicity, tenure, educational background, and functional background (Milliken \& Martins 1996, Williams \& O'Reilly 1998). The key question in diversity research is how differences between work group members affect group process and performance, as well as group member attitudes and subjective well-being. To address this question, diversity research has largely been guided by two research traditions: the social categorization perspective and the information/decision-making perspective (Williams \& O'Reilly 1998). This is not to say, however, that these are well-articulated theoretical perspectives in diversity research. Often they represent a more loosely defined emphasis on either the preference to work with similar others or the value of diverse information, knowledge, and perspectives.

The starting point for the social categorization perspective is the notion that similarities and differences between work group members form the basis for categorizing self and others into groups, distinguishing between similar ingroup members and dissimilar outgroup members. In diverse groups, this may mean that people distinguish subgroups

\section{Social}

categorization

perspective:

differences between

work group members may engender the classification of others as either ingroup/similar or outgroup/dissimilar, categorizations that may disrupt group process

Information/ decision-making perspective: diversity may introduce differences in knowledge, expertise, and perspectives that may help work groups reach higher quality and more creative and innovative outcomes 
within the work group. People tend to favor ingroup members over outgroup members, to trust ingroup members more, and to be more willing to cooperate with them (Brewer 1979, Brewer \& Brown 1998, Tajfel \& Turner 1986). The result of such categorization processes may be that work groups function more smoothly when they are homogeneous than when they are more diverse, and that group members are more satisfied with and attracted to the group when it is homogeneous and they are similar to the other group members. This analysis is corroborated by findings of, for instance, higher group cohesion (e.g., O'Reilly et al. 1989), lower turnover (e.g., Wagner et al. 1984), and higher performance (e.g., Murnighan \& Conlon 1991) in more homogeneous groups.

The social categorization perspective is complemented by the similarity/attraction perspective (Williams \& O'Reilly 1998), which does not concern social groups but rather focuses on interpersonal similarity (primarily in attitudes and values) as determinants of interpersonal attraction (Berscheid \& Reis 1998, Byrne 1971). The similarity/attraction perspective arrives at the same basic prediction as the social categorization perspective in diversity research, that people prefer to work with similar others (Jackson 1992).

In contrast to the social categorization (and similarity/attraction) perspective, the information/decision-making perspective emphasizes the positive effects of work group diversity. The starting point for this perspective is the notion that diverse groups are likely to possess a broader range of task-relevant knowledge, skills, and abilities, and members with different opinions and perspectives. This gives diverse groups a larger pool of resources that may be helpful in dealing with nonroutine problems. It may also set the stage for more creative and innovative group performance because the need to integrate diverse information and reconcile diverse perspectives may stimulate thinking that is more creative and prevent groups from moving to premature consensus on issues that need careful consideration (van Knippenberg et al. 2004). Corroborating this analysis, some studies find an association of diversity with higher performance and innovation (e.g., Bantel \& Jackson 1989).

In their simplest form (a main effect of diversity), neither analysis is supported. Evidence for the positive effects as well as for the negative effects of diversity is highly inconsistent (Bowers et al. 2000, Webber \& Donahue 2001, Williams \& O'Reilly 1998) and raises the question of whether, and how, the perspectives on the positive and the negative effects of diversity can be reconciled and integrated. Because the information/decision-making perspective focuses on task performance, whereas the social categorization perspective seems to put the relational aspect more center stage, some scholars have concluded that diversity may be good for group performance while at the same time it is bad for interpersonal relations and attitudes toward the work group (e.g., Triandis et al. 1994). Given the relationship between group interaction and cohesiveness on the one hand and group performance on the other hand (De Dreu \& Weingart 2003, Mullen \& Copper 1994), however, it is difficult to see how the outcomes described by the social categorization and the information/decisionmaking perspectives could occur simultaneously. Indeed, there hardly seems to be evidence for both occurring at the same time (but see Keller 2001).

One thing that stands out in this respect is that the field has been dominated by studies focusing on "main effects," testing relationships between dimensions of diversity and outcomes without taking potentially moderating variables into account (Jackson \& Joshi 2004, Pelled et al. 1999). Narrative reviews and meta-analyses alike seem to corroborate the conclusions that this main effects approach is unable to account for the effects of diversity adequately (Bowers et al. 2000, Webber \& Donahue 2001, Williams \& O'Reilly 1998). It seems time to declare the bankruptcy of the main effects approach and 
to argue for models that are more complex and that consider moderating variables in explaining the effects of diversity. Accordingly, the present review largely disregards studies of potential main effects in favor of studies identifying moderators of the effects of diversity.

This focus on moderators is important not only to identify when diversity may be expected to have positive or negative effects, but also because it is informative about the processes underlying the influence of work group diversity (i.e., moderator effects observed may corroborate conclusions about the processes in operation). Attention to these processes is important, because another major impediment to the advancement of the field is a tendency to assume rather than assess mediating processes. When a social categorization perspective is argued to predict negative effects of diversity and these are observed, the implicit conclusion is that social categorization processes occurred even when no empirical evidence for such processes is provided. In similar vein, often the occurrence of information/decision-making processes is concluded from the observation of positive effects of diversity on group performance without evidence regarding the processes taking place during group interaction. The predicted outcome is not necessarily evidence of the predicted process, however, and relying on outcomes to determine process runs the risk of resulting in misleading conclusions. The field may thus benefit from more attention to the processes translating work group diversity into outcomes, and the current review emphasizes studies that shed light on these mediating processes. First, however, we address another issue that emerged more recently-the possibility that conceptualizations of diversity that are more complex may yield more insight into the effects of diversity.

\section{CONCEPTUALIZING DIVERSITY}

Diversity may be seen as a characteristic of a social grouping (i.e., group, organization, so- ciety) that reflects the degree to which there are objective or subjective differences between people within the group (without presuming that group members are necessarily aware of objective differences or that subjective differences are strongly related to more objective differences). Such a definition and similar definitions coined by others (see above) leave unanswered a couple of important questions about how to deal with diversity conceptually, however, and some of these are quite salient in current research in diversity. Our review of the field suggests that four issues in this respect especially warrant attention: first, the possibility to better understand the effects of diversity by distinguishing between different types of diversity; second, the potential added value of moving beyond the study of demographic and functional diversity; third, the potential added value of conceptualizations of diversity that move beyond simple dispersion; and fourth, the notion that diversity's effects may be better understood if the influence of different dimensions of diversity is studied in interactions rather than as additive effects.

\section{Typologies of Diversity}

To introduce some higher-order structure in diversity research, a number of researchers have proposed typologies that may be used to classify different dimensions of diversity. These typologies include the distinction between readily observable demographic attributes (e.g., gender, race/ethnicity, age) that may be less job related and less easily discernable, and more job-related attributes such as differences in educational or functional background (Jackson 1992, Jehn et al. 1999, Milliken \& Martins 1996, Pelled et al. 1999, Schneider \& Northcraft 1999, Tsui et al. 1992; cf. Harrison et al. 1998). In addition, a number of researchers have argued that it is also important to take into account differences that may not be readily visible but are not always job-related either, such as differences in personality, attitudes, and values (Bowers et al. 2000, Harrison et al. 1998, Jehn et al. 1999). 
The question from the current perspective is, Do these typologies help in making sense of the effects of diversity?

Some researchers have proposed that demographic diversity, as well as diversity in personality, values, and attitudes, has negative effects on group performance and affectiveevaluative responses to the group, whereas diversity on more information-related dimensions, such as education and functional background, is more likely to have positive effects on group performance (Jehn et al. 1999, Pelled et al. 1999). Although this reasoning makes intuitive sense, it does not seem to be supported by the data. In support of the moderating role of diversity type, Jehn et al. (1999) found that informational diversity was positively related to group performance and commitment, whereas perceived value diversity (which does not necessarily reflect actual value diversity; cf. Harrison et al. 2002) was negatively related to group performance and group member satisfaction, intent to remain, and commitment. Contrary to predictions, however, demographic diversity was unrelated to group performance and was positively related to member satisfaction, intent to remain, and commitment, as well as to perceived work group performance. Pelled et al.'s (1999) hypotheses implied that functional diversity would be positively related to group performance, whereas demographic diversity would be negatively related to group performance, but neither type of diversity was related to group performance.

Other studies incorporating both demographic and informational dimensions of diversity report very similar relationships for, on the one hand, demographic diversity and presumably more job-related dimensions of diversity and, on the other hand, outcomes such as group performance, information use, and learning as well as team member satisfaction and commitment (Dahlin et al. 2005, Schippers et al. 2003, van der Vegt \& Bunderson 2005). Bunderson \& Sutcliffe (2002) report positive and negative relationships with team process and performance for different forms of informational diversity. In addition, there are also other reports of positive effects of demographic diversity (e.g., Bantel \& Jackson 1989) and negative effects of informational diversity (e.g., Simons et al. 1999) that run against the proposed moderating role of diversity type. Together these findings suggest that the distinction between diversity types is not associated with differential relationships with outcome variables. Most importantly, perhaps, meta-analyses do not support the notion of type of diversity as moderator of the positive versus the negative effects of diversity either-although it should be noted that these meta-analyses only covered a subset of the studies that could potentially have been included. In a meta-analysis of 13 studies, Bowers et al. (2000) distinguished gender, personality, attitude, and ability diversity and found no reliable relationship between any form of diversity and group performance. In a meta-analysis of 24 studies, Webber \& Donahue (2001) distinguished between highly job-related and less job-related diversity and found no reliable relationships for either form of diversity, neither with group performance nor with group cohesiveness.

An important conclusion to emerge from the current state of the art is that, contrary to what seems popular belief, the positive versus the negative effects of diversity are not associated with job-related informational diversity versus less job-related demographic diversity, neither for group performance nor for more affective/evaluative responses to the group. Interestingly, this means not only that organizations should be a bit more cautious in their enthusiasm for functional diversity, but also that they can be more optimistic about the possibilities to benefit from demographic diversity.

The inability to reliably link the positive and negative effects of diversity to types of diversity has led van Knippenberg et al. (2004) to propose that diversity research abandon attempts to explain the effects of diversity through typologies of diversity. In contrast, they propose that all dimensions of diversity 
may in principle elicit social categorization processes as well as information/decisionmaking processes, because all dimensions of diversity in principle both provide a basis for differentiation and may be associated with differences in task-relevant information and perspectives. Following this conclusion, and in deviation from earlier reviews (e.g., Milliken \& Martins 1996, Williams \& O'Reilly 1998), we do not structure the current review by diversity dimension, but rather we aim to highlight the processes that may be engendered by diversity and the contingencies of these processes.

\section{Beyond Demographic and Functional Diversity}

Perhaps understandably, diversity research has mainly focused on demographic and functional/educational diversity. Other dimensions of diversity that may be less easily captured by the existing typologies have received less attention, although they may be equally relevant to our understanding of group functioning. For instance, a growing number of studies link diversity in group member personality (mostly conceptualized in terms of the five-factor model of personality; Costa \& Macrae 1992) to group performance and more processes-related measures, such as team social integration (Barrick et al. 1998; Barry \& Stewart 1997; Harrison et al. 2002; Mohammed \& Angell 2003, 2004; Neuman et al. 1999; Neuman \& Wright 1999; Schneider et al. 1998; Van Vianen \& De Dreu 2001). So far, the picture emerging from these studies is quite inconsistent for the relationship between personality diversity and group process and performance, and further research addressing the contingencies of these relationships seems in order.

Others have also pointed to diversity in attitudes and values as an influence on group functioning (Hoffman \& Maier 1961). Here, too, findings are highly inconsistent. Some studies suggest that diversity in attitudes and values may be associated with negative out- comes (Harrison et al. 1998, 2002; Jehn \& Mannix 2001; also see Jehn et al. 1997, 1999). Some of these studies also show, however, that diversity in attitudes and values may be associated with positive outcomes (e.g., social integration) or may be unrelated to these outcomes (Harrison et al. 1998, 2002). The conclusion seems justified that diversity in attitudes and values, too, is worthy of research attention, but that we need more complex models to capture the potential influence of this diversity (cf. Harrison et al. 1998).

Socially shared cognition and affect typically is not considered in diversity research, but it arguably concerns dimensions of diversity. Research in socially shared cognition shows how individuals' understanding of their team and their task (conceptualized as task representations, Tindale et al. 1996; mental models, Cannon-Bowers et al. 1993; team schemas, Rentsch \& Hall 1994; or beliefs, Cannon \& Edmondson 2001) may be shared among group members to a greater or lesser extent [i.e., group members may be more or less similar in their understanding of the team and the task (Mohammed \& Ringseis 2001; also see Colquitt et al. 2002, Klein et al. 2001, Schneider et al. 2002)]. Because the level of sharedness may affect group performance (Mathieu et al. 2005), diversity in such team- and task-relevant cognitions deserves a place on the agenda of diversity research. In a similar vein, affective states (i.e., moods, emotions) may be shared to a greater or lesser extent (George 1990, Totterdell 2000, Totterdell et al. 1998), and the extent to which affect is shared has been shown to be related to group cooperation and conflict (Barsade et al. 2000). Affective diversity thus also warrants further research.

In sum, then, without denying the importance of the study of demographic diversity and diversity in functional and educational background, many other dimensions of diversity may influence group process and performance and therefore deserve research attention. This would seem to hold all the more because an understanding of the effects of 
demographic diversity seems at least partially to require an understanding of the more psychological dimensions that demographic differences are often presumed to be associated with, such as differences in attitudes, values, and perspectives (Beyer et al. 1997, Chattopadhyay et al. 1999, Cox et al. 1991). That is, analyses of demographic diversity to a certain extent treat demographic differences as proxies for deeper underlying differences (Priem et al. 1999), and investigating this proposed link as well as the processes governing the influence of these underlying differences may increase our understanding of the influence of demographic diversity.

\section{Beyond Dispersion}

Diversity research has typically operationalized diversity as the dispersion of group members' positions on a given dimension of diversity. Differences between group members are reflected in indices of the extent to which group members differ from each other, such as the standard deviation, Euclidian distance (Tsui et al. 1992), Blau (1977), and Teachman (1980) indices, and the coefficient of variation (for a detailed discussion of these measures, see Harrison \& Klein 2005, Harrison $\&$ Sin 2005), or simply by distinguishing groups with high versus low dispersion. Harrison \& Klein (2005) note that dimensions of diversity may differ in the extent to which they represent different positions on a continuum (e.g., attitudes), different nominal categories (e.g., gender), or different positions that are associated with greater or lesser power or status (e.g., educational level). Differences between group members on different dimensions may therefore mean different things, and Harrison \& Klein urge researchers to be more explicit about their conceptualization of diversity (e.g., whether it associated with status or power differentials), and to choose operationalizations that are commensurate with their conceptualization (also see Sørenson 2002, Williams \& Meân 2004).
Moreover, a couple of considerations suggest that there are potential benefits in complementing simple dispersion models with more complex conceptualizations and operationalizations of diversity (cf. Chan 1998, Kozlowski \& Bell 2003; also see the discussion of faultlines below). Research on relational demography (i.e., focusing on individual dissimilarity to the work group rather than on diversity) shows that being dissimilar to the work group more negatively affects people who are typically in majority positions in Western organizations (i.e., men, Caucasians) than it does people who are more often in the minority position (i.e., women, members of ethnic minorities; Chatman \& O'Reilly 2004, Tsui et al. 1992). To the extent that these outcomes for dissimilar group members affect group functioning and performance (e.g., through lower satisfaction, lower cohesion, and higher turnover), we might expect groups with, for instance, a female minority to function better than groups with a male minority. Whether or not this is the case needs to be tested, but the point is that simple dispersion models do not capture these more subtle effects because they treat a group with a male minority and a group with a comparable female minority (e.g., eight men and two women versus two men and eight women) as equally diverse (cf. Harrison \& Klein 2005).

Another consideration is that once a given background or perspective is represented by one or two members (e.g., members with a particular functional background within a cross-functional team), adding additional representatives of this background or perspective to the group might add relatively less to the group's potential to perform welli.e., sometimes diversity may be more a dichotomy (present versus absent) than a matter of degree. The effects of diversity may also be contingent on the mean level of the diversity dimension, as illustrated in Barsade et al.'s (2000) finding that the relationship of top management team diversity in positive affect with group conflict and cooperation was 
contingent on the mean level of positive affect in the team.

Such complex conceptualizations of diversity are acknowledged more in theoretical analyses than in empirical research, but they do seem to have the potential to enrich our understanding of the effects of diversity, and research following up on some of these notions should be highly worthwhile. In this respect, it is important to note that organizational surveys typically do not tap into the whole range of potential group compositions (e.g., work groups dominated by ethnic minorities tend to be rare in most samples), and more sophisticated conceptualizations of diversity might suggest that this poses a threat to the conclusions that may be reached on the basis of studies relying on more traditional dispersion models (Harrison \& Klein 2005).

\section{Faultlines: Interacting Dimensions of Diversity}

Traditionally, diversity research has focused on the effects of different dimensions of diversity in isolation or in additive models, not taking into account the possibility that the effects of a dimension of diversity may be contingent on diversity on other dimensions. Research on the salience of social categorizations (Oakes et al. 1994, Turner et al. 1987) and cross-categorization (Brewer 1995, Crisp et al. 2002) suggests that the correlation between different dimensions of differentiation influences the likelihood that diversity elicits subcategorization processes. It might therefore be better to think of work group diversity as an interaction of differences on different dimensions than to look only at the additive effects of dimensions of diversity.

Lau \& Murnighan (1998) coined the term "faultlines" to refer to combinations of correlated dimensions of diversity that yield a clear basis for differentiation between subgroups (i.e., implying both between-group differences and within-group similarity; Turner et al. 1987). A group composition in which all the men are relatively old and all the women are relatively young, for example, is more likely to elicit subcategorization than is a composition in which gender and age are unrelated. The stronger the diversity faultline, the more likely subcategorizations should be to arise, and the greater the chance of disruptions of group functioning.

In support of this proposition, $\mathrm{Li} \&$ Hambrick (2005) found that a faultline index was negatively related to self-rated group performance and that this relationship was mediated by relational conflict and behavioral integration (cf. social integration). Sawyer et al. (2005) compared informationally diverse decision-making groups that were ethnically homogeneous (all Caucasian) with groups that had an ethnic minority member present who was either also in the informational minority (i.e., a faultline) or in the informational majority (i.e., crosscutting informational and ethnic diversity), and reported that groups with crosscutting dimensions of diversity outperformed homogeneous and faultline groups. In a similar vein, Homan \& van Knippenberg (2003) showed that cross-categorization leads to a more favorable group process than does a faultline dividing the group equally (also see Phillips et al. 2004). More-indirect evidence of the disruptive influence of faultlines was provided by Lau \& Murnighan (2005), who found that faultlines are associated with less positive relationships of communication between subgroups with learning, psychological safety, group satisfaction, and expected group performance.

The evidence is less consistent, however, than one would like it to be. Lau \& Murnighan (2005) also observed that faultlines were associated with lower relational conflict, and higher satisfaction and psychological safety. Sawyer et al. (2005) did not observe differences between faultline and homogeneous groups, and Phillips et al. (2004) found that a faultline involving a single dissimilar member resulted in better decisionmaking performance than did a situation in which single-member dissimilarity and informational differences crosscut each other.
Faultlines: when positions on different dimensions of diversity are correlated, the combination of diversity on these dimensions may suggest a clear distinction between subgroups 
The possibility that faultlines have a curvilinear relationship with outcomes does not explain the above inconsistencies, but it hints at the possibility that the effects of faultlines are less straightforward than initially conceived. Both Gibson \& Vermeulen (2003) and Thatcher et al. (2003) found curvilinear relationships in which moderate faultlines were associated with outcomes that were more positive (team learning, morale, performance, and reduced conflict). However, both studies used faultline measures where moderate faultlines might also be labeled moderate crosscategorization, and it is unclear to what extent these findings point to the benefits of moderate faultlines (i.e., eliciting subgroup categorization) or of crosscutting dimensions of diversity (i.e., diversity without associated subgroup salience).

Earley \& Mosakowski (2000) showed that the faultline notion could also be applied to a single dimension of diversity when the dimension has multiple nominal categories. They found that teams with members from two different countries showed greater evidence of subcategorization and performed more poorly than did both nationalityhomogeneous teams and teams that consisted of members from several different countries (i.e., the two-nationality composition arguably represents a stronger faultline).

The faultline and cross-categorization concepts have added value in terms of explaining diversity effects, but the relationship between faultlines and outcomes is not clear-cut. In part, this may reflect problems with the operationalization of faultlines. It might be worthwhile, for instance, to consider the possibility that there are asymmetries in the effects of faultlines that are not captured by current faultline measures. For example, along similar lines as discussed in the previous section, a faultline between a male Caucasian minority and a female Asian majority might affect group functioning differently than a faultline between a male Caucasian majority and a female Asian minority. In part, the observed inconsistency in find- ings may also reflect a need to focus on the contingencies of the effects of faultlines (cf. Gibson \& Vermeulen 2003) because, for instance, salient categorizations only under certain circumstances translate into disruptive intergroup biases (van Knippenberg et al. 2004). And clearly, research actually assessing the categorization processes implied by faultline theory (cf. Earley \& Mosakowski 2000) is needed to explicitly test predictions about the assumed processes.

\section{PROCESSES UNDERLYING THE INFLUENCE OF DIVERSITY AND THEIR CONTINGENCIES}

An important issue is that not much clear evidence exists for the processes implied by the social categorization (and similarity/ attraction) and information/decision-making perspectives identified by Williams \& O'Reilly (1998). This is due in part to the fact that many studies did not include process measures. A complicating factor in this respect is that neither the social categorization perspective on work group diversity nor the information/decision-making perspective represents a clearly articulated theoretical framework; rather, the perspectives are more like loosely defined applications of social categorization theories and notions about group information processing and decision making.

In the following sections, we address the empirical evidence for the processes underlying the effects of work group diversity and the factors that moderate these processes. Most of the evidence in diversity research is not easily and unambiguously interpreted in terms of social categorization and information/decision-making processes, however, and a substantial part of our discussion concerns studies that may be consistent (to a greater or lesser extent) with the social categorization and information/decisionmaking perspectives without providing direct evidence to that effect. In that respect, we identify three (sets of) factors that are 
receiving increased research attention as moderators of the effects of diversity: interdependence, time, and diversity mind-sets.

\section{Social Categorization Processes}

Diversity research has typically applied insights from research in social categorization and intergroup relations in a straightforward way, predicting that differences between people may elicit social categorization processes (stereotypic perceptions of dissimilar others, subgroup formation, intergroup biases) that disrupt group functioning and lower affective/evaluative responses to the group. In support of this analysis, there is evidence that diversity may elicit subcategorization. Earley \& Mosakowski (2000) assessed subgroup categorization and common group identity (although the latter measure arguably reflects cohesiveness more than social categorization) and found that groups with stronger faultlines had a stronger sense of subgroups and a weaker common identity. Moreover, they found evidence that common identity mediated the relationship between faultlines and satisfaction (but not performance). These findings were not replicated in a second study, though.

Research on relational demography also yields evidence for social categorization processes, although this should be treated more carefully because, as noted above, individual dissimilarity does not necessarily reflect group diversity. Chattopadhyay et al. (2004b) found that dissimilarity to the work group lowered individuals' self-categorization as a member of the group. Randel (2002) found that group gender composition affected the salience of male group members' gender identity (cf. Mehra et al. 1998) and that identity salience moderated the relationship between gender composition and relational conflict (i.e., suggesting a translation of categorization into intergroup bias; also see Randel \& Jaussi 2003). Evidence that diversity affects social categorization thus is quite modest, and it would seem important for future research to estab- lish the validity of this basic tenet of the social categorization perspective on work group diversity.

A second question is whether there is evidence of an association of work group diversity with intergroup bias in perceptions, evaluations, and social interaction. Social categorization processes are presumed to engender more favorable attitudes toward ingroup than outgroup others, more trust, more willingness to cooperate, and generally smoother interaction with ingroup than with outgroup others. In line with this argument, Chatman \& Flynn (2001) found that demographic diversity was associated with lower self-rated team cooperativeness. Consistent with the idea that computer-mediated interaction removes social categorization cues (Sproull \& Kiesler 1986), Bhappu et al. (1997) found that computer-mediated communication in gender-diverse groups showed fewer signs of intergroup bias (operationalized as differential attention to same-gender versus othergender communication) than did face-to-face communication. Chattopadhyay (1999) observed in a study of relational demography that trust in peers mediated the negative relationship between individual dissimilarity and organizational citizenship behavior (see also Chattopadhyay \& George 2001). None of these studies presented direct evidence of social categorization processes, however, so caution is in order in concluding that these studies provide evidence of intergroup bias.

Research focusing on social/behavioral integration and relational conflict similarly yields evidence that is consistent with a social categorization interpretation. Randel's (2002) findings for the role of identity salience in relational conflict probably provide the most persuasive evidence of social categorization disrupting group process in diverse work groups. Other studies offer evidence that is more indirect because they included no direct measure of categorization (e.g., the association observed between diversity faultlines and behavioral integration by Li \& Hambrick 2005). Evidence of negative relationships 
between diversity and social integration (Harrison et al. 1998, 2002), and positive relationships between diversity and relational conflict (Pelled et al. 1999) that also mediated the relationship with outcomes (Bayazit \& Mannix 2003, Jehn et al. 1999, Knight et al. 1999, Mohammed \& Angell 2004), is consistent with the social categorization prediction. However, it does not prove that these relationships follow from social categorization processes rather than from other factors associated with diversity.

Complicating matters, evidence also links diversity to higher social integration and group identification (identification reflects self-categorization), and lower relational conflict (Polzer et al. 2002; cf. Swann et al. 2003). Building on research by Swann and colleagues on self-verification (being seen by others as one sees oneself; for an overview, see Swann et al. 2004), Polzer et al. (2002) tested interactions between congruence of group members' self-views and the views other group members have of them (arguably a proxy for selfverification) and demographic and functional diversity. They found that whereas higher diversity tended to be associated with more negative outcome when congruence was low, it actually tended to be associated with more positive outcome when congruence was high. For the social categorization perspective to account for the effects of diversity adequately, it would thus seem that it should also be able to incorporate positive relationships of diversity with group identification and group interaction (cf. van Knippenberg \& Haslam 2003).

A number of studies thus yield results that are consistent with a social categorization analysis of the effects of work group diversity. Surprisingly few studies, however, directly assessed social categorization processes, and results are inconsistent enough to raise doubts about the extent to which social categorization processes are in operation. Moreover, without supporting process evidence, some of the negative relationships between diversity and group process may also be interpreted as reflecting the consequences of misunder- standing and disagreement per se (i.e., a more dysfunctional side of information/decisionmaking processes) rather than social categorization. Empirical attention to the actual categorization processes therefore would be warranted to substantiate the social categorization analysis of work group diversity.

It might also be useful to extend social categorization (and similarity/attraction) analyses with insights from the study of social networks in organizations (Brass et al. 2004). Social network analysis has attempted to capture relationships between group members in terms of the strength and nature of their ties, and has proven useful in capturing the influence of diversity on the relationships formed by group members (Klein et al. 2004, Reagans \& Zuckerman 2001). Network analysis may help to paint a more elaborate picture of the social relations within a work group that moves beyond the relatively simple notion of a split in subgroups and thus enable a more fine-grained analysis of social categorization processes. Moreover, it may also prove useful in capturing the external (i.e., outside of the work group) network of group members as it may be affected by diversity (Reagans et al. 2004).

Models that are more sophisticated and that focus on the contingencies of subcategorization and intergroup bias (van Knippenberg et al. 2004) also seem in order. In this respect, research on the salience of social categorizations (Oakes et al. 1994, Turner et al. 1987) shows that there is more to social categorization than just differences between people. As reflected in the notion of diversity faultlines, some combinations of differences (i.e., those that result in high between-group differences and within-group similarities) are more likely to elicit subcategorizations than are others. In this sense, diversity is also context: In more-diverse organizations, work group diversity may be less salient (cf. Martins et al. 2003; also see Brief et al. 2005, Joshi et al. 2005).

In addition, for diversity to elicit a particular categorization, the categorization also has 
to make sense within individuals' psychological frame of reference (an issue that diversity research so far has hardly touched upon): In order to become salient, a categorization should not only capture similarities and differences between people, but should also be meaningful to the individual (Turner et al. 1987). Moreover, as van Knippenberg et al. (2004) argue, it is intergroup bias (favoring one's own subgroup) that may disrupt group process and not categorization per se (i.e., the perception of subgroups), and categorization only translates into intergroup bias under certain circumstances. Thus, diversity research might benefit from a more fine-grained analysis of the factors that elicit social categorization as well as of the factors that translate social categorization into intergroup bias.

\section{Information/Decision-Making Processes}

At the core of the information/decisionmaking perspectives lies the notion that work group diversity may be associated with differences in information, knowledge, and perspectives, and that this diversity may benefit group performance. These informational differences are not limited to what are often seen as informational or job-relevant dimensions of diversity (Tsui \& O'Reilly 1989, van Knippenberg et al. 2004). As van Knippenberg et al. (2004) outline, this implies that at the core of the positive effects of diversity emphasized in the information/decision-making perspective lies elaboration of task-relevant information-the group-level exchange, processing, and integration of diverse information and perspectives (cf. Hinsz et al. 1997). In line with this analysis, Earley \& Mosakowski (2000) found that a measure of team communication that seems to be closely aligned with this notion of elaboration mediated the relationship of group diversity and performance (although this finding was not replicated in a second study), and Dahlin et al. (2005) found that (moderate) diversity was associated with greater information use.
Related to the proposed role of elaboration of task-relevant information is the notion that divergent viewpoints may stimulate team reflexivity. Team reflexivity refers to the team's careful consideration and discussion of its functioning and is proposed to result in team learning and improved team performance (Schippers et al. 2005; West 1996, 2002). Just as diversity may stimulate elaboration of task-relevant information, divergent perspectives on the task that may be associated with diversity may invite a team to reflect on its own functioning. In support of this proposition, Schippers et al. (2003) found that team reflexivity mediated the (moderated) relationship between diversity and team performance, commitment, and satisfaction. Providing further support for this perspective, Gibson \& Vermeulen (2003) found that diversity may be positively related to team learning behavior (cf. reflexivity), and Van der Vegt \& Bunderson (2005) found that team learning behavior partly mediated the relationship between expertise diversity and team performance.

A number of researchers working from a related perspective have pointed to the role of task conflict-disagreements about the task performed (Jehn et al. 1999, Lovelace et al. 2001, Pelled et al. 1999). Diversity is proposed to have the potential to stimulate task conflict through its associated differences in viewpoints, ideas, and opinions, and task conflict is argued to engender more careful consideration of the task at hand. Consistent with this notion, Jehn et al. (1999) found that task conflict mediated the positive relationship between informational diversity and group performance. Inconsistent with this reasoning, however, they also found that perceived value diversity positively correlated with task conflict (cf. Jehn \& Mannix 2001), while perceived value diversity was negatively related to performance. Pelled et al. (1999) also found evidence that functional background diversity was positively related to task conflict (as do Lovelace et al. 2001), but found no relationship between diversity and group performance. 
Raising further doubts about the proposed role of task conflict, the notion that task conflict mediates the positive influence of diversity on group performance is at odds with the meta-analytic finding that task conflict is negatively related to group performance (De Dreu \& Weingart 2003). Indeed, as van Knippenberg et al. (2004) argue, although task conflict might engender elaboration of task-relevant information and thus foster group performance under certain conditions (cf. Lovelace et al. 2001), task conflict does not necessarily do so, nor is task conflict a prerequisite for elaboration of task-relevant information to occur. Accordingly, it may be the elaboration of task-relevant information per se and not task conflict that drives the positive effects of diversity, but studies assessing both task conflict and group-level information processing are required to address this issue.

If positive effects of diversity on performance flow from group information processing, then the positive effects of diversity should be more likely on tasks with stronger information-processing and/or decisionmaking requirements (van Knippenberg et al. 2004). In support of this proposition, Jehn et al. (1999) found that informational diversity was more positively related to group performance on less-routine tasks, and Bowers et al.'s (2000) meta-analysis showed that diversity was positively related to group performance on more complex tasks but was negatively related on simpler tasks. Although this is no evidence for the actual elaboration of information assumed to underlie this moderating effect, these findings are consistent with the information/decision-making perspective.

There thus is some evidence for the processes implied in the information/decisionmaking perspective, although studies assessing these processes are generally somewhat lacking. Moreover, there seems to be some controversy about the role of task conflict. It therefore seems that diversity research may benefit from more theoretical as well as empirical attention to the information process- ing and decision-making processes that are presumed to drive the positive effects of diversity. In addition, in view of the lack of support for an overall positive effect of diversity, theoretical models of the contingencies of information/decision-making processes are required. Research on social information processing, for instance, suggests that processing motivation and ability are key determinants of in-depth processing of information (Chaiken \& Trope 1999). Motivation and ability have received little attention in diversity research, yet they potentially also are important determinants of groups' use of their diversity of information and perspectives (van Knippenberg et al. 2004).

\section{Social Categorization Processes As Moderator of Information/ Decision-Making Processes}

The social categorization perspective and the information/decision-making perspective have largely developed along separate lines, and there are few studies considering the interaction between social categorization and information/decision-making processes. Yet, because intergroup bias may render individuals less open to communication from dissimilar others (van Knippenberg 1999), intergroup bias engendered by diversity may disrupt group information processing and thus stand in the way of realizing the potential benefits of diversity (van Knippenberg et al. 2004).

Consistent with this proposition, Jehn et al. (1999) found that higher perceived value diversity and demographic diversity were associated with less-positive relationships between informational diversity and indicators of group performance. In a similar vein, Phillips et al.'s (2004) finding that groups that were split equally along a faultline dealt less successfully with their informational diversity is consistent with this argument (also see Homan \& van Knippenberg 2003). Neither study includes measures of social categorization processes, though, so some caution is 
in order in attributing these findings to the disruptive influence of social categorization processes. Lau \& Murnighan's (2005) observation that faultlines disrupted the positive relationship between intersubgroup communication (cf. Bhappu et al. 1997) and positive group outcomes is also in line with this argument. Their finding that faultlines were also associated with less relational conflict and greater psychological safety and satisfaction raises some doubts about a straightforward social categorization interpretation of these findings, however. Although the available evidence thus seems reasonably consistent with the proposition that diversity may disrupt group information processing, the evidence for the actual operation of social categorization and information/decision-making processes is largely missing.

A possibility that has received less attention is that social categorization processes may also stimulate group information processing. A line of research by Phillips and colleagues hints at this possibility, suggesting that informationally diverse groups that contain a member who is dissimilar to the other members of the group are more likely to make effective use of their informational diversity than are more-homogeneous groups, presumably because dissimilarity alerts the group to potential associated differences in information (Phillips 2003; Phillips et al. 2004, 2005; Phillips \& Loyd 2005). However, because measures of categorization are missing from these studies, it is not clear whether these effects can be attributed to social categorization processes.

Either way, the work by Phillips and colleagues raises the following questions: Under which conditions is greater diversity beneficial to a group's use of distributed information, and under which conditions is diversity more likely to disrupt group information processing? As Phillips et al. (2004) show, whether social categorization processes point to a solo minority member or to equal-sized subgroups may be one factor (but see Sawyer et al. 2005), but a more comprehensive account of the contingencies of these effects awaits future research.

\section{Cooperation and Interdependence}

Group members may depend to a greater or lesser extent on each other for task performance (i.e., task interdependence; Wageman 1995) and for outcomes that may flow from task performance (i.e., outcome interdependence; Wageman 1995). Moreover, this interdependence may be more cooperative or competitive in nature (i.e., own and others' interests may align or conflict). A number of researchers have proposed that the degree and nature of interdependence between group members moderates the relationship between work group diversity and outcomes. Such a moderating role is consistent with both the social categorization and the information/decision-making perspective. From a social categorization perspective, higher, more cooperative interdependence between group members may focus group members on the common group identity and distract from subgroup categorizations (Gaertner \& Dovidio 2000). In addition, interdependence may also facilitate intergroup contact and be conducive to more harmonious relations between different groups (Pettigrew 1998). At the same time, the need to collaborate may also set the stage for group information processing because it may invite information exchange and discussion. From both perspectives, cooperative interdependence would thus be expected to be associated with effects of diversity that are more positive.

In support of this notion, Chatman et al. (1998; also see Chatman \& Spataro 2005) in a study of relational demography showed that in groups with collectivistic norms emphasizing cooperation (versus individualistic norms emphasizing competition and independence), dissimilarity is more positively associated with group process and performance. Mohammed \& Angell (2004) found that gender diversity was associated with relational 
conflict only when group members were less concerned with cooperative relations, and that time urgency (an individual difference variable) diversity was positively related to relational conflict when team process was low rather than high in terms of cooperation, communication, and task-oriented leadership. It should be noted, however, that they did not obtain similar relationships for ethnic diversity and extraversion diversity, and that they observed these relationships at time 1 but not at time 2. Schippers et al. (2003) reported that diversity was positively related to team reflexivity (i.e., arguably an indicator of information/decision processes), self-rated group performance, and satisfaction for highoutcome interdependence and negatively for low-outcome interdependence. Jehn et al. (1999) observed that demographic diversity was more positively related to satisfaction and commitment when task interdependence was higher. Van der Vegt \& Janssen (2003) found that diversity was only positively related to innovative behavior when both task and outcome interdependence were high, which suggests that it may be worthwhile to consider task and outcome interdependence in combination.

Whereas these studies are generally consistent with the notion that greater cooperative interdependence is associated with more positive relationships between diversity and outcomes, two studies suggest that the issue may be more complex and that interdependence may be a double-edged sword. Ely (2004) found that tenure and age diversity interacted with a team process measure including cooperation, such that higher scores were associated with more negative relationships between diversity and performance. Jehn \& Bezrukova (2004) observed that work group cultures that were more cooperative were associated with more positive relationships between diversity and performance for some dimensions of diversity but with more negative relationships for another dimension, while group culture did not affect this relationship for yet other dimensions of diversity.
These findings suggest that the role of cooperation and interdependence may be more complex than is currently conceived, although it is also possible that more mundane explanations in terms of differences in measurement and specific conceptualizations would account for some of these observations. Either way, it would be valuable if future research would focus more on the processes underlying the effects of cooperation and interdependence and develop more-comprehensive accounts of the role of cooperation and interdependence vis-à-vis social categorization and information/decision-making perspectives on the effects of work group diversity.

\section{Time/Team Tenure}

Harrison and colleagues in particular have advanced the idea that the effects of diversity may change over time as groups gain extended experience working with each other (Harrison et al. 1998, 2002). Extended tenure may lead group members to find out that initial stereotype-based impressions about fellow group members were wrong (cf. Pettigrew 1998), thus attenuating the effects of social categorization processes. At the same time, extended tenure may also bring to the surface more hidden differences that may negatively affect group process. Extended team tenure may thus be associated with less negative as well as more negative effects of diversity. Harrison et al. (1998) link the first to surface-level demographic dimensions of diversity and the second to deep-level, more hidden dimensions of diversity.

Consistent with Harrison et al.'s (1998) proposition, a number of studies yield evidence that associations between demographic diversity and outcomes may become less negative over time (Chatman \& Flynn 2001; Harrison et al. 1998, 2002; Pelled et al. 1999; Watson et al. 1993; cf. Earley \& Mosakowski 2000, Sacco \& Schmitt 2005), and that the associations between more hidden dimensions of diversity and outcomes may become more negative over time (Harrison et al. 1998, 
2002). However, other studies yield evidence inconsistent with Harrison et al.'s (1998) proposition. Watson et al. (1998) found that demographic diversity was more negatively related to outcomes over time. Schippers et al. (2003) observed that more hidden dimensions of diversity were more strongly (and positively) related to group process and performance when team tenure was low rather than high. Mohammed \& Angell (2004) found no difference between the correlates of surfacelevel and deep-level diversity between two measurement points.

Aside from the fact that these inconsistent findings corroborate our earlier claim that typologies of diversity do not explain the differential effects of diversity, these findings underscore that time/team tenure is a factor that may moderate the effects of diversity. Models that are more elaborate would help to predict the exact nature of this moderating effect, however. In this respect, future research may also take into account the possibility that groups need extended tenure to benefit from differences - that is, that the positive effects of diversity need some time to emerge (van Knippenberg et al. 2004).

\section{Diversity Mind-Sets}

The notion that people prefer to work with similar others in homogeneous groups features prominently in accounts of the effects of diversity. Perhaps somewhat surprisingly then, only a limited number of studies have actually focused on what people think about diversity, and on the possibility that people's ideas about diversity may influence the effects of diversity. This seems to be changing. On the individual level of analysis, some researchers have examined attitudes toward diversity and beliefs about the value of diversity (Hostager \& De Meuse 2002, Strauss et al. 2003, van Knippenberg \& Haslam 2003). On the group and organizational levels of analysis, attempts have been made to assess shared cognition about diversity in the form of diversity climates, cultures, or perspec- tives (Chen \& Eastman 1997, Ely \& Thomas 2001, Kossek \& Zonia 1993, Mor Barak et al. 1998). Although some of these studies merely focus on evaluations of diversity, others also try to capture people's understanding of how to deal with diversity (cf. mental models; Ely \& Thomas 2001, van Ginkel \& van Knippenberg 2003). To capture these partly overlapping approaches to people's diversity cognitions, van Knippenberg et al. (2005) proposed the label "diversity mind-sets," which refers to people's understanding of how diversity may affect their work group or organization, their understanding of the appropriate way to deal with diversity, and their associated evaluations of diversity.

The general idea driving research on what may be summarized as diversity mind-sets is that the effects of diversity should be more positive in contexts where individuals, groups, and organizations have more favorable beliefs about and attitudes toward diversity, are more focused on harvesting the benefits of diversity, and have a better understanding of how to realize these benefits. Diversity mind-sets favoring diversity may thus be expected to prevent intergroup bias as well as to stimulate the integration of diverse information, viewpoints, and perspectives (Chen \& Eastman 1997, Ely \& Thomas 2001, van Knippenberg \& Haslam 2003). That is, diversity mindsets may moderate social categorization as well as information/decision-making processes. Rather than testing this moderating role, however, research has largely concentrated on developing measures of aspects of diversity mind-sets and studying their antecedents (Hostager \& De Meuse 2002, Kossek \& Zonia 1993, Mor Barak et al. 1998, Roberson et al. 2001, Strauss et al. 2003).

Even so, there is some evidence that diversity mind-sets favoring diversity and describing ways of realizing the benefits of diversity may be associated with effects of diversity that are more positive. R.J. Ely \& D.A. Thomas (manuscript submitted; also see Ely \& Thomas 2001) show that racial diversity is more positively related to performance 
at bank branches that are focused on learning from diversity (cf. Richard et al. 2003). Homan et al. (2004) show that gender-diverse decision-making groups are more likely to use their informational diversity when they believe in the value of diversity. van Ginkel \& van Knippenberg (2003) find that groups reach higher-quality decisions when they have a shared understanding of how to deal with their informational diversity, and van Knippenberg et al. (2003) report more positive relationships between diversity and identification for group members who believe more in the value of diversity. Thus, although research on diversity mind-sets is still at an embryonic stage, it does seem to have promise.

\section{CURVILINEAR RELATIONSHIPS}

From notions about the role of group information processing follows the idea that the effects of diversity might be curvilinear. To benefit from the diversity of information, expertise, and perspectives that may be associated with dimensions of differentiation, group members should be able to understand and integrate the contributions of dissimilar others. As group members differ more in background, experience, and expertise, however, it becomes more likely that they do not share a common frame of reference (i.e., "speak the same language") that allows in-depth understanding of diverse others' input. Thus, the potentially positive effects of diversity on group performance may only obtain up to a certain level of diversity, beyond which the lack of a common frame of reference may get in the way of fully appreciating all group members' contributions (van Knippenberg et al. 2004).

In support of this proposition, researchers have reported evidence of curvilinear relationships in which moderate diversity is associated with more positive outcomes than is lower as well as higher diversity (Brodbeck 2003; Dahlin et al. 2005; V. Gonzalez-Roma, M.A. West, \& C. Borrill, manuscript submit- ted; Richard et al. 2004). Contrary to this proposition, however, Richard et al. (2004) and Dahlin et al. (2005) also find evidence for the opposite curvilinear relationship, as do Gibson \& Vermeulen (2003). Further complicating matters, Van der Vegt \& Bunderson (2005) found, contingent on level of team commitment, both U-shaped (high commitment) and inverted U-shaped (low commitment) relationships for the association between expertise diversity and team learning and performance.

The evidence for curvilinear effects of diversity thus is far from straightforward. Yet, echoing similar conclusions in the previous section, enough indications exist to warrant a closer look at curvilinear relationships in addition to linear relationships (also see the curvilinear effects observed for diversity faultlines). This seems especially important because the notion of curvilinear relationships also hints at the possibility that some of the inconsistent findings in diversity research might be due to restriction of range effects. That is, contingent on which part of the range is sampled, a curvilinear relationship in the population might yield a positive, a null, or a negative relationship between diversity and outcomes.

\section{CONCLUSIONS}

How much progress has research in organizational diversity made since Williams \& O'Reilly (1998) assessed the state of the art? Clearly, with the increased attention to more complex conceptualizations of diversity, to the processes mediating the effects of work group diversity, and to the contingencies of these processes, our current understanding of the effects of work group diversity on group process and performance goes well beyond the 1998 state of the art. At the same time, however, much is still unclear about the effects of diversity. The increasing attention to the mediators and moderators of diversity's effects is exactly what the field needed, but some important steps still need to be made. 
An important issue is that there seems to be too much ad hoc theorizing and too little development of theoretical frameworks that are more widely applied in the study of diversity. Directly related to this is the lack of empirical attention to the processes that are presumed to underlie the effects of diversity. As the current review shows, very few studies actually capture the range of processes that are implied by the reasoning underlying hypotheses and that should ideally be assessed for a proper test of the implied theoretical model. In combination with the inconsistent evidence for most propositions, this seriously impairs the field's progress. Especially when results do not confirm predictions, it would seem important to know whether diversity did not elicit the presumed processes or whether these processes were not associated with the outcomes as predicted. Also, when different perspectives may predict the same outcome through different processes, information about process would seem essential to theory development. Clearer articulation of the theoretical models driving diversity research makes more apparent which processes should be assessed to test these models, and more consistent application of these models will make clearer to what extent they provide valid accounts of the effects of diversity. In similar vein, studies of the moderators of the effects of diversity should work from clear links with the processes predicted by these theoretical models and should assess whether the proposed moderators indeed affect these processes.

To establish the causality implied in theoretical models of diversity, it is also essential that survey research is complemented by controlled experiments. An additional advantage of controlled experiments is that they typically allow for superior assessment of group processes (i.e., by behavioral observation rather than by relying on self-reports; Weingart 1997).

We have identified a number of avenues for future research that we deem to be particularly important. The development of more complex conceptualizations of diversity seems an important step in advancing our understanding of work group diversity. Further application of insights from social categorization research about the salience of social categories would also seem valuable. The emerging attention to diversity faultlines is a promising step in this direction, but this would also include research on the role of the extent to which the categorization makes sense within the individuals' psychological frame of reference and on the role of the wider organizational and societal context in which the group is embedded (e.g., the diversity of the organization as a whole). In similar vein, a focus on the factors that affect the translation of social categorization into intergroup bias would seem important. Diversity research may also benefit from greater application of insights from research on social information processing and group decision making to develop theoretical models of information/decisionmaking processes. Finally, exploring possible curvilinear effects of diversity in addition to linear effects may lead to important new insights and contribute to explaining some of the inconsistencies in diversity research. Given the value of an understanding of diversity at work for organizations and societies that are becoming ever more diverse, it would seem important to take on these research challenges and invest in the continued progress of this field.

\section{SUMMARY POINTS}

1. Typologies of diversity (most commonly differentiating forms of demographic and functional diversity) do not explain the differential effects that work group diversity may have on group process and performance. 
2. Diversity research needs to move beyond conceptualizations and operationalizations of diversity simply as dispersion on a single dimension of diversity. Rather, it should conceptualize diversity as a combination of different dimensions of differentiation, take asymmetries into account, and be open to nonlinear effects.

3. Diversity research should pay more theoretical and empirical attention to the social categorization and information/decision-making processes presumed to underlie the effects of diversity on work group performance.

4. Diversity research should pay more attention to the moderators of social categorization, intergroup bias, and information/decision-making processes.

\section{ACKNOWLEDGMENTS}

We are grateful to Susan Fiske for her guidance and advice and to Jeremy Dawson, Dave Harrison, Susan Mohammed, Kathy Phillips, Charles O'Reilly, Bill Swann, and Rolf van Dick for their valuable comments on a previous draft of this article.

\section{LITERATURE CITED}

Bantel K, Jackson S. 1989. Top management and innovations in banking: Does the composition of the team make a difference? Strateg. Manage. 7. 10:107-24

Barrick MR, Stewart GL, Neubert MJ, Mount MK. 1998. Relating member ability and personality to work-team processes and team effectiveness. F. Appl. Psychol. 83:377-91

Barry B, Stewart GL. 1997. Composition, process, and performance in self-managed groups: the role of personality. 7. Appl. Psychol. 82:62-78

Barsade SG, Ward AJ, Turner JDF, Sonnenfeld JA. 2000. To your heart's content: a model of affective diversity in top management teams. Admin. Sci. Q. 45:802-36

Bayazit M, Mannix EA. 2003. Should I stay or should I go? Predicting team members' intent to remain in the team. Small Group Res. 34:290-321

Berscheid E, Reis HT. 1998. Attraction and close relationships. In The Handbook of Social Psychology, ed. DT Gilbert, ST Fiske, G Lindzey, pp. 193-281. New York: McGraw-Hill

Beyer JM, Chattopadhyay P, George E, Glick WH, Ogilvie DT, Pugliese D. 1997. The selective perception of managers revisited. Acad. Manage. 7. 40:716-37

Bhappu AD, Griffith TL, Northcraft GB. 1997. Media effects and communication bias in diverse groups. Organ. Behav. Hum. Decis. Process. 70:199-205

Blau PM. 1977. Inequality and Heterogeneity. New York: Free Press

Bowers CA, Pharmer JA, Salas E. 2000. When member homogeneity is needed in work teams. a meta-analysis. Small Group Res. 31:305-27

Brass DJ, Galaskiewicz J, Greve HR, Tsai W. 2004. Taking stock of networks and organizations: a multilevel perspective. Acad. Manage. 7. 47:795-817

Brewer MB. 1979. In-group bias in the minimal intergroup situation: a cognitive-motivational analysis. Psychol. Bull. 86:307-24

Brewer MB. 1995. Managing diversity: the role of social identities. In Diversity in Work Teams: Research Paradigms for a Changing Workplace, ed. S Jackson, MN Ruderman, pp. 47-68. Washington, DC: Am. Psychol. Assoc.

Brewer MB, Brown RJ. 1998. Intergroup relations. In Handbook of Social Psychology, ed. DT Gilbert, ST Fiske, pp. 554-94. Boston: McGraw-Hill 
Brief AP, Umphress EE, Dietz J, Butz RM, Burrows J, Scholten L. 2005. Community matters: realistic group conflict theory and the impact of diversity. Acad. Manage. 7. 48:830-44

Brodbeck F. 2003. Contradiction as an inbibitor and facilitator of group performance. Presented at Eur. Cong. Work Organ. Psychol., Lisbon

Bunderson JS, Sutcliffe KM. 2002. Comparing alternative conceptualizations of functional diversity in management teams: process and performance effects. Acad. Manage. 7. 45:87593

Byrne D. 1971. The Attraction Paradigm. New York: Academic

Cannon M, Edmondson A. 2001. Confronting failure: antecedents and consequences of shared beliefs about failure in organizational work groups. F. Organ. Behav. 22:161-77

Cannon-Bowers JA, Salas E, Converse S. 1993. Shared mental models in expert team decision making. In Individual and Group Decision Making: Current Directions, ed. NJ Castellan, pp. 221-46. Hillsdale, NJ: Erlbaum

Chaiken S, Trope Y. 1999. Dual Process Theories in Social Psychology. New York: Guilford

Chan D. 1998. Functional relations among constructs in the same content domain at different levels of analysis: a typology of composition models. F. Appl. Psychol. 83:234-46

Chatman JA, Flynn FJ. 2001. The influence of demographic heterogeneity on the emergence and consequences of cooperative norms in work teams. Acad. Manage. 7. 44:956-74

Chatman JA, O'Reilly CA. 2004. Asymmetric reactions to work group sex diversity among men and women. Acad. Manage. 7. 47:193-208

Chatman JA, Polzer JT, Barsade SG, Neale MA. 1998. Being different yet feeling similar: the influence of demographic composition and organizational culture on work processes and outcomes. Admin. Sci. Q. 43:749-80

Chatman JA, Spataro SE. 2005. Using self-categorization theory to understand relational demography-based variations in people's responsiveness to organizational culture. Acad. Manage. 7. 48:321-31

Chattopadhyay P. 1999. Beyond direct and symmetrical effects: the influence of demographic dissimilarity on organizational citizenship behavior. Acad. Manage. 7. 42:273-87

Chattopadhyay P, George E. 2001. Examining the effects of work externalization through the lens of social identity theory. 7. Appl. Psychol. 86:781-88

Chattopadhyay P, George E, Lawrence SA. 2004b. Why does dissimilarity matter? Exploring self-categorization, self-enhancement, and uncertainty reduction. F. Appl. Psychol. 89:892900

Chattopadhyay P, Glick WH, Miller CC, Huber GP. 1999. Determinants of executive beliefs: comparing functional conditioning and social influence. Strateg. Manage. 7. 20:763-89

Chattopadhyay P, Tluchowska M, George E. 2004a. Identifying the ingroup: a closer look at the influence of demographic dissimilarity on employee social identity. Acad. Manage. Rev. 29:180-202

Chen CC, Eastman W. 1997. Toward a civic culture for multicultural organizations. F. Appl. Behav. Sci. 33:454-70

Colquitt JA, Noe RA, Jackson CL. 2002. Justice in teams: antecedents and consequences of procedural justice climate. Pers. Psychol. 55:83-109

Costa PTJ, McCrae RR. 1992. The NEO-PI-R: Revised Personality Inventory (NEO-PI-R). Odessa, FL: Assess. Resourc.

Cox T, Lobel S, McLeod P. 1991. Effects of ethnic group cultural differences on cooperative and competitive behavior on a group task. Acad. Manage. 7. 34:827-47

Crisp RJ, Ensari N, Hewstone M, Miller NW. 2002. A dual-route model of crossed categorization effects. In European Review of Social Psychology, ed. W Stroebe, M Hewstone, pp. 35-74. Hove, UK/Philadelphia, PA: Psychol. Press 


\section{Provides a thorough analysis of different ways to conceptualize and operationalize diversity, and outlines how the conceptualization adopted may affect conclusions of diversity research.}

Dahlin KB, Weingart LR, Hinds PJ. 2005. Team diversity and information use. Acad. Manage. 7. 48:1107-23

De Dreu CKW, Weingart LR. 2003. Task and relationship conflict, team performance, and team member satisfaction: a meta-analysis. F. Appl. Psychol. 88:741-49

Earley PC, Mosakowski E. 2000. Creating hybrid team cultures: an empirical test of transnational team functioning. Acad. Manage. 7. 43:26-49

Ely RJ. 2004. A field study of group diversity, participation in diversity education programs, and performance. 7. Organ. Behav. 25:755-80

Ely RJ, Thomas DA. 2001. Cultural diversity at work: the effects of diversity perspectives on work group processes and outcomes. Admin. Sci. Q. 46:229-73

Epitropaki O, Martin R. 1999. The impact of relational demography on the quality of leadermember exchanges and employees' work attitudes and well-being. 7. Occup. Organ. Psychol. $72: 237-40$

Gaertner SL, Dovidio JF. 2000. Reducing Intergroup Bias. The Common Ingroup Identity Model. Philadelphia, PA: Psychol. Press

George JM. 1990. Personality, affect and behavior in groups. 7. Appl. Psychol. 75:107-16

Gibson C, Vermeulen F. 2003. A healthy divide: subgroups as a stimulus for team learning behavior. Admin. Sci. Q. 48:202-39

Guzzo RA, Dickson MW. 1996. Teams in organizations: recent research on performance and effectiveness. Anпu. Rev. Psychol. 47:307-38

Harrison DA, Klein KJ. 2006. What's the difference? Diversity constructs as separation, variety, or disparity in organizations. Acad. Manage. Rev. In press

Harrison DA, Price KH, Bell MP. 1998. Beyond relational demography: time and the effects of surface- and deep-level diversity on work group cohesion. Acad. Manage. 7. 41:96-107

Harrison DA, Price KH, Gavin JH, Florey AT. 2002. Time, teams, and task performance: changing effects of surface- and deep-level diversity on group functioning. Acad. Manage. 7. 45:1029-45

Harrison DA, Sin HS. 2005. What is diversity and how should it be measured? In Handbook of Workplace Diversity, ed. AM Konrad, P Prasad, JK Pringle, pp. 191-216. Newbury Park, CA: Sage

Hinsz VB, Tindale RS, Vollrath DA. 1997. The emerging conceptualization of groups as information processors. Psychol. Bull. 121:43-64

Hoffman LR, Maier NRF. 1961. Quality and acceptance of problem solutions by members of homogeneous and heterogeneous groups. 7. Abnorm. Soc. Psychol. 62:401-7

Homan AC, van Knippenberg D. 2003. The beneficial effects of cross-categorizing informational and demographical diversity in groups. Presented at Eur. Cong. Work Organ. Psychol., Lisbon

Homan AC, van Knippenberg D, Van Kleef GA, De Dreu CKW. 2004. Managing group diversity beliefs to increase performance in diverse teams: Promoting diversity helps! Presented at Annu. Meet. Soc. Ind. Organ. Psychol., Chicago, IL

Hostager TJ, De Meuse KP. 2002. Assessing the complexity of diversity perceptions: breadth, depth, and balance. F. Bus. Psychol. 17:189-206

Ilgen DR, Hollenbeck JR, Johnson M, Jundt D. 2005. Teams in organizations: from inputprocess-output models to IMOI models. Annu. Rev. Psychol. 56:517-43

Jackson SE. 1992. Team composition in organizational settings: issues in managing an increasingly diverse work force. In Group Process and Productivity, ed. S Worchel, W Wood, JA Simpson, pp. 136-80. Newbury Park, CA: Sage

Jackson SE, Joshi A. 2004. Diversity in social context: a multi-attribute, multilevel analysis of team diversity and sales performance. F. Organ. Behav. 25:675-702 
Jackson SE, Joshi A, Erhardt NL. 2003. Recent research on team and organizational diversity: SWOT analysis and implications. 7. Manage. 29:801-30

Jehn KA, Bezrukova K. 2004. A field study of group diversity, workgroup context, and performance. F. Organ. Behav. 25:703-29

Jehn KA, Chadwick C, Thatcher S. 1997. To agree or not to agree: the effects of value congruence, member diversity, and conflict on workgroup outcomes. Int. F. Confl. Manage. $8: 287-305$

Jehn KA, Mannix EA. 2001. The dynamic structure of conflict: a longitudinal study of intragroup conflict and group performance. Acad. Manage. 7. 44:238-51

Jehn KA, Northcraft GB, Neale MA. 1999. Why differences make a difference: a field study of diversity, conflict, and performance in workgroups. Admin. Sci. Q. 44:741-63

Joshi A, Liao H, Jackson SE. 2005. Cross-level effects of workplace diversity on sales performance and pay. Acad. Manage. F. In press

Keller RT. 2001. Cross-functional project groups in research and new product development: diversity, communications, job stress, and outcomes. Acad. Manage. 7. 44:547-59

Kerr NL, Tindale RS. 2004. Group performance and decision making. Annu. Rev. Psychol. 55:623-55

Klein KJ, Conn AB, Smith DB, Sorra JS. 2001. Is everyone in agreement? An exploration of within-group agreement in employee perceptions of the work environment. F. Appl. Psychol. 86:3-16

Klein KJ, Lim BC, Saltz JL, Mayer DM. 2004. How do they get there? An examination of the antecedents of centrality in team networks. Acad. Manage. 7. 47:952-63

Knight D, Pearce CL, Smith KG, Olian JD, Sims HP, et al. 1999. Top management team diversity, group process, and strategic consensus. Strateg. Manage. 7. 20:445-65

Kossek EE, Zonia SC. 1993. Assessing diversity climate: a field study of reactions to employer efforts to promote diversity. F. Organ. Behav. 14:61-81

Kozlowski SWJ, Bell BS. 2003. Work groups and teams in organizations. In Handbook of Psychology: Industrial and Organizational Psychology, ed. WC Borman, DR Ilgen, RJ Klimoski, pp. 333-75. London: Wiley

Lau DC, Murnighan JK. 1998. Demographic diversity and faultlines: the compositional dynamics of organizational groups. Acad. Manage. Rev. 23:325-40

Lau DC, Murnighan JK. 2005. Interactions within groups and subgroups: the effects of demographic faultlines. Acad. Manage. 7. 48:645-59

Li J, Hambrick DC. 2005. Factional groups: a new vantage on demographic faultlines, conflict, and disintegration in work teams. Acad. Manage. 7. 48:794-813

Lovelace K, Shapiro DL, Weingart LR. 2001. Maximizing cross-functional new product teams' innovativeness and constraint adherence: a conflict communications perspective. Acad. Manage. 7. 44:779-93

Martins LL, Milliken FJ, Wiesenfeld BM, Salgado SR. 2003. Racioethnic diversity and group members' experiences: the role of the racioethnic diversity of the organizational context. Group Organ. Manage. 28:75-106

Mathieu JE, Heffner TS, Goodwin GF, Cannon-Bowers JA, Salas E. 2005. Scaling the quality of teammates' mental models: equifinality and normative comparisons. F. Organ. Behav. 26:37-56

Mehra A, Kilduff M, Brass DJ. 1998. At the margins: a distinctiveness approach to the social identity and social networks of underrepresented groups. Acad. Manage. F. 41:441-52

Milliken FJ, Martins LL. 1996. Searching for common threads: understanding the multiple effects of diversity in organizational groups. Acad. Manage. Rev. 21:402-33
Introduced the concept of faultline to diversity research in a way that sparked a still-expanding research interest. 
Mohammed S, Angell LC. 2003. Personality heterogeneity in teams: Which differences make a difference for team performance? Small Group Res. 34:651-77

Mohammed S, Angell LC. 2004. Surface- and deep-level diversity in workgroups: examining the moderating effects of team orientation and team process on relationship conflict. $\mathcal{F}$. Organ. Behav. 25:1015-39

Mohammed S, Ringseis E. 2001. Cognitive diversity and consensus in group decision making: the role of inputs, processes, and outcomes. Organ. Behav. Hum. Decis. Process. 85:310-35

Mor Barak ME, Cherin DA, Berkman S. 1998. Organizational and personal dimensions of diversity climate: ethnic and gender differences in employee perceptions. F. Appl. Behav. Sci. 31:82-104

Mullen B, Copper C. 1994. The relation between group cohesiveness and performance: an integration. Psychol. Bull. 115:210-27

Murnighan JK, Conlon DE. 1991. The dynamics of intense work groups: a study of British string quartets. Admin. Sci. Q. 36:165-86

Neuman GA, Wagner SH, Christiansen ND. 1999. The relationship between work-team personality composition and the job performance of teams. Group Organ. Manage. 24:2845

Neuman GA, Wright J. 1999. Team effectiveness: beyond skills and cognitive ability. F. Appl. Psychol. 84:376-89

Oakes PJ, Haslam SA, Turner JC. 1994. Stereotyping and Social Reality. Malden, MA: Blackwell Sci.

O'Reilly CA, Caldwell DF, Barnett WP. 1989. Work group demography, social integration, and turnover. Admin. Sci. Q. 34:21-37

Pelled LH, Eisenhardt KM, Xin KR. 1999. Exploring the black box: an analysis of work group diversity, conflict, and performance. Admin. Sci. Q. 44:1-28

Pettigrew TF. 1998. Intergroup contact theory. Annu. Rev. Psychol. 49:65-85

Phillips KW. 2003. The effects of categorically based expectations on minority influence: the importance of congruence. Personal. Soc. Psychol. Bull. 29:3-13

Phillips KW, Loyd DL. 2006. When surface and deep-level diversity collide: the effects on dissenting group members. Organ. Behav. Hum. Decis. Process. 99:143-60

Phillips KW, Mannix EA, Neale MA, Gruenfeld DH. 2004. Diverse groups and information sharing: the effects of congruent ties. F. Exp. Soc. Psychol. 40:497-510

Phillips KW, Northcraft GB, Neale MA. 2006. Surface-level diversity and information sharing: When does deep-level diversity help? Group Process. Intergroup Relat. In press

Polzer JT, Milton LP, Swann WBJ. 2002. Capitalizing on diversity: interpersonal congruence in small work groups. Admin. Sci. Q. 47:296-324

Priem RL, Lyon DW, Dess GG. 1999. Inherent limitations of demographic proxies in top management team heterogeneity research. 7. Manage. 25:935-53

Randel AE. 2002. Identity salience: a moderator of the relationship between group gender composition and work group conflict. 7. Organ. Behav. 23:749-66

Randel AE, Jaussi KS. 2003. Functional background identity, diversity, and individual performance in cross-functional teams. Acad. Manage. 7. 46:763-74

Reagans R, Zuckerman EW. 2001. Networks, diversity, and productivity: the social capital of corporate R\&D teams. Organ. Sci. 12:502-17

Reagans R, Zuckerman EW, McEvily B. 2004. How to make the team: Social networks versus demography as criteria for designing effective teams. Admin. Sci. Q. 49:101-33

Rentsch JR, Hall RJ. 1994. Members of great teams think alike: a model of team effectiveness and schema similarity among team members. In Advances in Interdisciplinary Studies of Work Teams, ed. MM Beyerlein, DA Johnson, pp. 223-61. Stamford, CT: JAI 
Richard O, McMillan A, Chadwick K, Dwyer S. 2003. Employing an innovation strategy in radically diverse workforce. Group Organ. Manage. 28:107-26

Richard OC, Barnett T, Dwyer S, Chadwick K. 2004. Cultural diversity in management, firm performance, and the moderating role of entrepreneurial orientation dimensions. Acad. Manage. 7. 47:255-66

Roberson L, Kulik CT, Pepper MB. 2001. Designing effective diversity training: Influence of group composition and trainee experience. F. Organ. Behav. 22:871-85

Sacco JM, Schmitt N. 2005. A dynamic multilevel model of demographic diversity and misfit effects. F. Appl. Psychol. 90:203-31

Sawyer JE, Houlette MA, Yeagley EL. 2006. Decision performance and diversity structure: comparing faultlines in convergent, crosscut, and racially homogeneous groups. Organ. Behav. Hum. Decis. Process. 99:1-15

Schippers MC, Den Hartog DN, Koopman P. 2006. Reflexivity in teams: a measure and correlates. Appl. Psychol. Int. Rev. In press

Schippers MC, Den Hartog DN, Koopman PL, WienkJA. 2003. Diversity and team outcomes: the moderating effects of outcome interdependence and group longevity and the mediating effect of reflexivity. F. Organ. Behav. 24:779-802

Schneider B, Salvaggio AN, Subirats M. 2002. Climate strength: a new direction for climate research. 7. Appl. Psychol. 87:220-29

Schneider B, Smith DB, Taylor S, Fleenor J. 1998. Personality and organizations: a test of the homogeneity of personality hypothesis. F. Appl. Psychol. 83:462-70

Schneider SK, Northcraft GB. 1999. Three social dilemmas of workforce diversity in organizations: a social identity perspective. Hum. Relat. 52:1445-67

Simons T, Pelled LH, Smith KA. 1999. Making use of difference: diversity, debate, and decision comprehensiveness in top management teams. Acad. Manage. 7. 42:662-73

Sørenson JB. 2002. The use and misuse of the coefficient of variation in organizational demography research. Sociol. Meth. Res. 30:475-91

Sproull L, Kiesler S. 1986. Reducing social context cues: electronic mail in organizational communication. Manage. Sci. 32:1492-512

Strauss JP, Connerley ML, Ammermann PA. 2003. The "threat hypothesis," personality, and attitudes toward diversity. F. Appl. Behav. Sci. 39:32-52

Swann WB, Polzer JT, Seyle DC, Ko SJ. 2004. Finding value in diversity: verification of personal and social self-views in diverse groups. Acad. Manage. Rev. 29:9-27

Swann WBJ, Kwan VSY, Polzer JT, Milton LP. 2003. Fostering group identification and creativity in diverse groups: the role of individuation and self-verification. Personal. Soc. Psychol. Bull. 29:1396-406

Tajfel H, Turner JC. 1986. The social identity theory of intergroup behavior. In Psychology of Intergroup Relations, ed. S Worchel, W Austin, pp. 7-24. Chicago: Nelson-Hall

Teachman JD. 1980. Analysis of population diversity. Sociol. Meth. Res. 8:341-62

Thatcher SMB, Jehn KA, Zanutto E. 2003. Cracks in diversity research: the effects of diversity faultlines on conflict and performance. Group Decis. Negot. 12:217-41

Tindale RS, Smith CM, Thomas LS, Filkins J, Sheffey S. 1996. Shared representations and asymmetric social influence in small groups. In Understanding Group Behavior: Consensual Action by Small Groups, ed. E Witte, JH Davis, pp. 81-83. Mahwah, NJ: Erlbaum

Totterdell P. 2000. Catching moods and hitting runs: mood linkage and subjective performance in professional sport teams. 7. Appl. Psychol. 85:848-59

Totterdell P, Kellett S, Teuchmann K, Briner RB. 1998. Evidence of mood linkage in work groups. F. Personal. Soc. Psychol. 74:1504-15 


Provides an
integrative model
bridging and
extending the
social
categorization
perspective and the
information/decision-
making
perspective, the
two main traditions
in diversity
research.

Provides an integrative model bridging and extending the social categorization perspective and the information/decisionmaking perspective, the two main traditions in diversity
Triandis HC, Kurowski LL, Gelfand MJ. 1994. Workplace diversity. In Handbook of Industrial and Organizational Psychology, Vol. 4, ed. HC Triandis, MD Dunnette, LM Hough, pp. 769-827. Palo Alto, CA: Consult. Psychol. Press. 2nd ed.

Tsui AS, Egan TD, O'Reilly CA. 1992. Being different: relational demography and organizational attachment. Admin. Sci. Q. 37:549-79

Tsui AS, O'Reilly CA. 1989. Beyond simple demographic effects: the importance of relational demography in superior-subordinate dyads. Acad. Manage. 7. 32:402-23

Tsui AS, Porter LW, Egan TD. 2002. When both similarities and dissimilarities matter: extending the concept of relational demography. Hum. Relat. 55:899-929

Turner JC, Hogg MA, Oakes PJ, Reicher SD, Wetherell MS. 1987. Rediscovering the Social Group: A Self-Categorization Theory. Oxford, UK: Blackwell

Van der Vegt GS, Bunderson JS. 2005. Learning and performance in multidisciplinary teams: the importance of collective team identification. Acad. Manage. 7. 48:532-47

Van der Vegt GS, Janssen O. 2003. Joint impact of interdependence and group diversity on innovation. F. Manage. 29:29-51

van Ginkel WP, van Knippenberg D. 2003. The role of shared mental models for informational diversity in group decision-making. Presented at Eur. Assoc. Exp. Soc. Psychol. Small Group Meet. on Small Group Decision Making: Motiv. Cogn., Amsterdam

van Knippenberg D. 1999. Social identity and persuasion: reconsidering the role of group membership. In Social Identity and Social Cognition, ed. D Abrams, MA Hogg, pp. 315-31. Oxford, UK: Blackwell Sci.

van Knippenberg D, De Dreu CKW, Homan AC. 2004. Work group diversity and group performance: an integrative model and research agenda. F. Appl. Psychol. 89:100822

van Knippenberg D, Haslam SA. 2003. Realizing the diversity dividend: exploring the subtle interplay between identity, ideology, and reality. In Social Identity at Work: Developing Theory for Organizational Practice, ed. SA Haslam, D van Knippenberg, MJ Platow, N Ellemers, pp. 61-77. New York/Hove: Psychol. Press

van Knippenberg D, Haslam SA, Platow MJ. 2003. Work group diversity and work group identification: diversity as an aspect of group identity. Presented at 11th Eur. Congr. Work Organ. Psychol., Lisbon

van Knippenberg D, van Ginkel WP, Homan AC, Kooij-de Bode HJM. 2005. Diversity mind sets: a new focus in diversity research. Presented at 12th Eur. Congr. Work Organ. Psychol., Istanbul

Van Vianen AEM, De Dreu CKW. 2001. Personality in teams: its relationship to social cohesion, task cohesion, and team performance. Eur. F. Work Organ. Psychol. 10:97-120

Wageman R. 1995. Interdependence and group effectiveness. Admin. Sci. Q. 40:140-80

Wagner GW, Pfeffer J, O'Reilly CA. 1984. Organizational demography and turnover. Admin. Sci. Q. 29:74-92

Watson W, Johnson L, Merritt D. 1998. Team orientation, self-orientation, and diversity in task groups: their connection to team performance over time. Group Organ. Manage. 23:161-88

Watson W, Kumar K, Michaelson L. 1993. Cultural diversity's impact on interaction process and performance: comparing homogeneous and diverse task groups. Acad. Manage. $\mathcal{F}$. 36:590-602

Webber SS, Donahue LM. 2001. Impact of highly and less job-related diversity on work group cohesion and performance: a meta-analysis. 7. Manage. 27:141-62

Weingart L. 1997. How did they do that? The ways and means of studying group process. Res. Organ. Behav. 19:189-39 
West MA. 1996. Reflexivity and work group effectiveness: a conceptual integration. In Handbook of Work Group Psychology, ed. MA West, pp. 555-79. Chichester, UK: Wiley

West MA. 2002. Sparkling fountains or stagnant ponds: an integrative model of creativity and innovation implementation in work groups. Appl. Psychol. Int. Rev. 51:355-87

Williams HM, Meân LJ. 2004. Measuring gender composition in work groups: a comparison of existing models. Organ. Res. Methods 7:456-74

Williams KY, O'Reilly CA. 1998. Demography and diversity in organizations: a review of 40 years of research. Res. Organ. Behav. 20:77-140
Reviews diversity research up to 1998.

Complements the current article for a full overview of the field. 
Annual Review of Psychology

\section{Contents}

\section{Prefatory}

Research on Attention Networks as a Model for the Integration of

Psychological Science

Michael I. Posner and Mary K. Rothbart ......................................... 1

\section{Cognitive Neuroscience}

The Representation of Object Concepts in the Brain

Alex Martin

\section{Depth, Space, and Motion}

Perception of Human Motion

Randolph Blake and Maggie Shiffrar

\section{Form Perception (Scene Perception) or Object Recognition}

Visual Object Recognition: Do We Know More Now Than We Did 20

Years Ago?

Fessie 7. Peissig and Michael 7. Tarr

\section{Animal Cognition}

Causal Cognition in Human and Nonhuman Animals: A Comparative, Critical Review

Derek C. Penn and Daniel 7. Povinelli

\section{Emotional, Social, and Personality Development}

The Development of Coping 
Biological and Genetic Processes in Development

The Neurobiology of Stress and Development

Megan Gunnar and Karina Quevedo....

\section{Development in Societal Context}

An Interactionist Perspective on the Socioeconomic Context of

Human Development

Rand D. Conger and M. Brent Donnellan

\section{Culture and Mental Health}

Race, Race-Based Discrimination, and Health Outcomes Among African Americans Vickie M. Mays, Susan D. Cochran, and Namdi W. Barnes

\section{Personality Disorders}

Assessment and Diagnosis of Personality Disorder: Perennial Issues and an Emerging Reconceptualization Lee Anna Clark

\section{Social Psychology of Attention, Control, and Automaticity}

Social Cognitive Neuroscience: A Review of Core Processes Matthew D. Lieberman

\section{Inference, Person Perception, Attribution}

Partitioning the Domain of Social Inference: Dual Mode and Systems Models and Their Alternatives Arie W. Kruglanski and Edward Orehek

\section{Self and Identity}

Motivational and Emotional Aspects of the Self Mark R. Leary.

Social Development, Social Personality, Social Motivation, Social Emotion

Moral Emotions and Moral Behavior Fune Price Tangney, Feff Stuewig, and Debra F. Mashek 
The Experience of Emotion

Lisa Feldman Barrett, Batja Mesquita, Kevin N. Ochsner, and Fames 7. Gross.....

\section{Attraction and Close Relationships}

The Close Relationships of Lesbian and Gay Men

Letitia Anne Peplau and Adam W. Fingerbut ... 405

\section{Small Groups}

Ostracism

Kipling D. Williams 425

\section{Personality Processes}

The Elaboration of Personal Construct Psychology Beverly M. Walker and David A. Winter

\section{Cross-Country or Regional Comparisons}

Cross-Cultural Organizational Behavior

Michele 7. Gelfand, Miriam Erez, and Zeynep Aycan

\section{Organizational Groups and Teams}

Work Group Diversity

Daan van Knippenberg and Michaéla C. Schippers ...

\section{Career Development and Counseling}

Work and Vocational Psychology: Theory, Research, and Applications Nadya A. Fouad

\section{Adjustment to Chronic Diseases and Terminal Illness}

Health Psychology: Psychological Adjustment to Chronic Disease Annette L. Stanton, Tracey A. Revenson, and Howard Tennen 


\section{Research Methodology}

Mediation Analysis

David P. MacKinnon, Amanda 7. Fairchild, and Matthew S. Fritz

Analysis of Nonlinear Patterns of Change with Random Coefficient

Models

Robert Cudeck and Feffrey R. Harring

\section{Indexes}

Cumulative Index of Contributing Authors, Volumes 48-58 639

Cumulative Index of Chapter Titles, Volumes 48-58 ... 644

\section{Errata}

An online log of corrections to Annual Review of Psychology chapters (if any, 1997 to the present) may be found at http://psych.annualreviews.org/errata.shtml 